\title{
Gamification Techniques to Re-Invent Public Healthcare Services - A Case Study
}

\author{
Mohamed Buheji \\ International Inspiration Economy Project- Bahrain \\ E-mail: buhejim@gmail.com
}

Received: May 14, 2019 Accepted: May 30, 2019 Online published: June 4, 2019

doi:10.5296/ijhrs.v9i2.14888

URL: https://doi.org/10.5296/ijhrs.v9i2.14888

\begin{abstract}
Interest is growing in gamification of the different public services to enhance the development through engagement of the concerned stakeholders. A review of the gamification applied in healthcare services through inspiration labs is illustrated. The paper investigates how the different gamification constructs and techniques help in re-inventing the public healthcare services.

The findings of the study are presented around the opportunities and learning that comes from gamifying the change initiatives. The paper shows how researchers and practitioners can gamify complex public services, as healthcare sectors, and create a change to different activities that would lead to a behavioural change of the targeted community. The study makes a recommendation to considers more in-depth empirical studies that enhance the integration of gamification in more public services.
\end{abstract}

Keywords: gamification, social change, gamification psychology, inspiration labs, motivational mechanisms, re-inventing public services, healthcare services

\section{Introduction}

Gamification is an innovative approach that foster motivation in non-game contexts. This paper investigates how gamification can help in creating change and re-inventing the public healthcare services in any country, taking the context of the healthcare system in the Kingdom of Bahrain. Buheji (2019a), McGonigal (2011).

A review of the different game designs indicators is done after reviewing the concept of gamification and its critical success factors. After that, different motivational perspectives are analysed. Then psychology of gamification design is discussed. Requirements of Gamification in any public services business model is discussed with a focus on healthcare services. Heckhausen and Heckhausen (2008). 
To implement the gamification, the game elements in the re-invented healthcare services are stratified. The theoretical review results are compared to the effectiveness of the re-invented healthcare services design. The motivational and emotional involvement during the healthcare service delivery creates a differentiated influence that is investigated later. The basic idea of gamification in changing healthcare services is to use its motivational power and environment influencing behaviour to foster better learning and awareness. This influence the psychological perspectives. Buheji (2019a), Deci and Ryan (1985).

\section{Literature Review}

\subsection{What Is Gamification and What Differentiate}

Gamification helps to turn a routine into something exciting through developing better interaction. By turning events into games, we can change many regular tasks into something exciting, and make it easier to learn or sustain a behaviour too. This can be very beneficial for social change. Rughiniș (2013), McGonigal (2011), Deterding et al. (2011).

Gamification is a method that applies the principles of games, and games design techniques into real life activities. The concept uses the fun and addictive part of games to increase the engagement and motivation of people to achieve specific tasks through optimising status and achievements. Robinson and Bellotti (2013), Heckhausen and Heckhausen (2008).

The sense of games creates urgent optimism with an immediate desire to overcome a challenge while building better relationships. Games create the urge to explore and activates our curiosity to find meaning.

Gamification use games design elements which are made of four constructs, which has to be achieved to reach a specific goal while giving feedback about progress towards that goal. Hense and Mandl (2012), McGonigal (2011).

\subsection{How to Use Gamification for Social Change?}

Since the application of gamification is comprehensive, this paper focuses on the non-digital realisations in public services, focusing on exemplary indicators and constructs used in gamification. For example, the constructs create codification, i.e. like colour coding that points to the accumulated activities within the gamification environment. The codification is similar to badges in games which are visual representations of achievements, which can be collected within the gamification environment. Rughiniș (2013), McGonigal (2011).

Visual management is used to resemble the leaderboards in games where the players are listed and usually are ranked by their success. Codification of status of achievement also represents the progress bars are used to provide information about the current status of a player towards a goal. The 'hit rate' is used to resemble performance graphs and to provide information about a players' performance, compared to previous performance. McGonigal (2011).

The idea of gamification helps to build self-determination which creates psychological needs for competence, autonomy, and social relatedness. The fulfilment of these needs fosters 
intrinsic inspiration, which helps people to execute challenging yet exciting service development nature. This helps to effectively and interactively to execute the task that integrates with the targeted needs. Gamification helps to define a way of penalising those who choose to do something poorly. Buheji and Ahmed (2018), Buheji and Ahmed (2017), Ryan and Deci (2000), Skinner (1963).

\subsection{The Psychology of Gamification Design}

If you ask gamification designers about their goals, they will probably tell you is to make the user's life simple. When gamification designers work on a product, they put maximum effort into creating something that gives users the straightest path to their desired outcome.

Organisations are increasingly using gamification in a wide range of applications, but little work has been done to link gamification to psychological trait perspectives that change the behaviours of the targeted group. The gamification addresses the need for power and the need for affiliation. Thus internal processes, such as expectancies, estimations, and assessments, play a significant role in cognitive theories of motivation. McGonigal (2011), Deci and Ryan (1985).

Another psychological variable is performance orientation, and mastery orientation can be differentiated through both exceeding certain standards of peers and then self-defined standards. Skinner (1963).

The mechanisms of motivations make the stakeholders more likely to be motivated to achieve the goals of a given situation and foster mastery orientation regarding these goals. The stakeholders keep getting motivated to discover through experiential learning and thus to build the feeling of competence and autonomy. Sailer et al. (2017), Heckhausen and Heckhausen (2008).

Researchers constitute interest as a motivational variable that is content specific and evolves in interaction with the environment. At this moment, interest is both an effective and cognitive variable.

Motivational Mechanisms address interest and flow of the stakeholders for the situational context. The stakeholders are likely to be motivated if gamification enhances the feeling of flow by providing direct feedback. Sailer et al. (2017), Heckhausen and Heckhausen (2008).

The perspective of emotion focuses on the roles of emotions in cognitive and motivational processes. Emotions interact with these cognitive and motivational processes and can be influenced by instructional strategies. The stakeholders are likely to be motivated if gamification decreases negative feelings like fear, envy, and anger. In the same, while gamification increases positive feelings like sympathy and pleasure. Werbach and Hunter, (2012).

\subsection{Gamification and Inspiration Labs}

Gamification is based on iteration and emotion. Before we gamify any business we need first to understand it, observe the opportunities built in it, reflect our point of view, ideate about, 
prototype about and do playtesting, Domínguez et al. (2013). This precisely what inspiration labs do when trying to re-invent any business model. Inspiration labs help us to analyse the requirements, do research analysis, establish gamification frameworks, establish interdisciplinary teams, build rapid prototyping and experience playtesting. Buheji and Ahmed (2017), Robinson and Bellotti (2013), Werbach and Hunter (2012).

Buheji (2018) showed how inspiration labs techniques could solve any sophisticated socio-economic problems through the method of observation. Observation target to either find opportunities inside the problem or simplify the transformation by raising the capacity to realise the change in the specific community targeted. Throughout the inspiration lab, active participation, field visits, gamification, networking, surveys, individual and collective reflections are used to enhance the efficacy of observation, as Figure (1) shows.

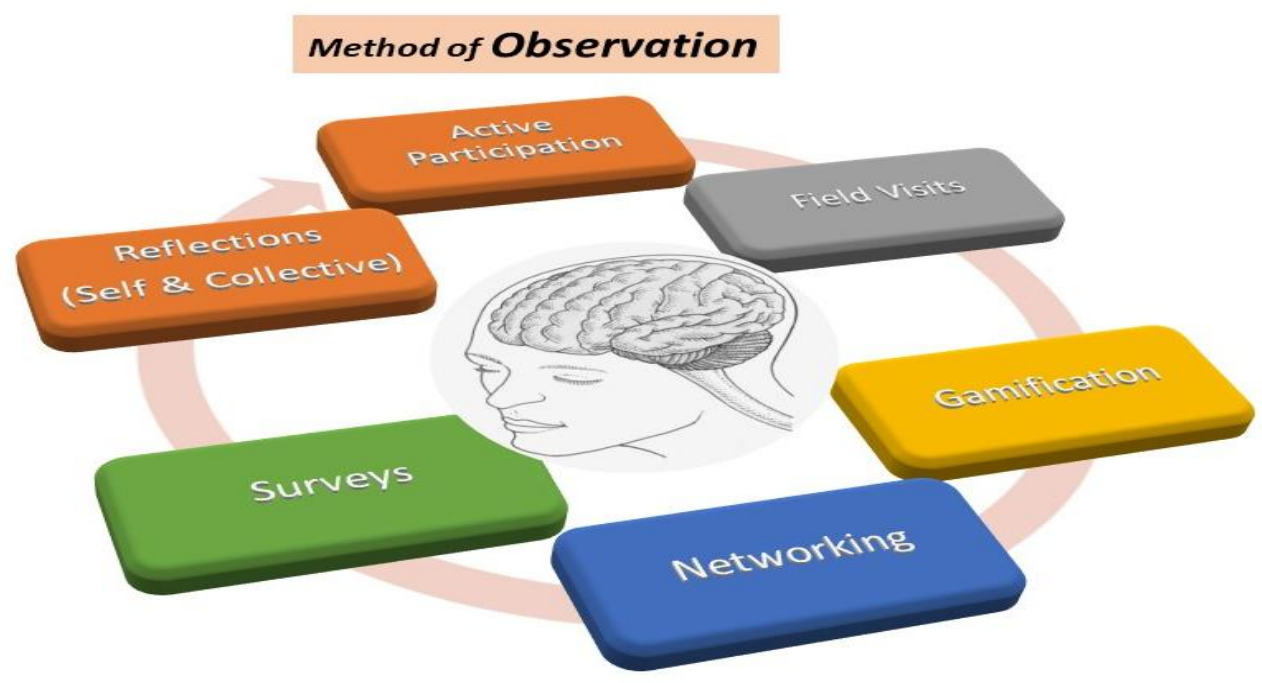

Figure 1. Illustrates the Gamification as part of the Method of Observation in Inspiration Labs

There have been different attempts to create lists of those game elements, which can be applied in gamification. Werbach and Hunter (2012) distinguished between the dynamics of gamification, which constitute the prominent picture aspects, mechanics, which describe the underlying processes, and components, which are specific instantiations of dynamics and mechanics.

Kapp (2012) lists typical game elements like goals, rules conflict, competition, cooperation, time, reward structures, feedback, levels, storytelling, the curve of interest and aesthetics. All these attempts should help to grasp how diverse game elements could look like, but they should be understood as non-exhaustive lists. McGonigal (2011).

\subsection{Constructs and Indicators of Gamification Techniques}

There are primary constructs for any gamification design. These key factors are mainly working to ensure the following leading indicators achieved: mechanical indicators, reward indicators, behaviour indicators and measurement indicators. Sailer et al. (2017), Deci and Ryan (1985). 


\section{Macrothink}

International Journal of Human Resource Studies

ISSN 2162-3058

2019, Vol. 9, No. 2

The constructs and indicators of gamification are influenced by behavioural game mechanics called in paper 'gamification techniques'. The gamification techniques are solely focused on human behaviour and can be in the form: feedback loops, progression, engagement loops, engagement and re-engagement optimisation. Thus these gamification techniques can be like: achievements badges, levels, leaderboards, progress bars, activity feeds, avatars (i.e. ideas for example), real-time feedback, challenges and quests, trophy case and mini-games within other activities. The gamification techniques help to build the gamification construct indicators, be it: mechanical-, rewards-, measurement- and behaviour-based. Hense and Mandl (2012).

\subsubsection{Mechanical Construct}

The first construct focus on mechanical indicators such as visual storytelling, visual cues, response objects, reward schedules, disincentives, access and social feedback.

\subsubsection{Rewards Construct}

The second construct focus on rewards indicators which includes: recognition, status, access and stuff.

\subsubsection{Measurement Construct}

The third construct focuses on rewards indicators which include: reputation, performance, quality, completion, quantity and time.

\subsubsection{Behaviour Construct}

The fourth construct focuses on rewards indicators which include: loyalty, mastery, quality and engagement.

\subsection{Using Gamification in Public Healthcare Services}

In socio-economic problem-solving, we need to introduce gamification without being getting too involved with current restrictions. To encourage interactive healthcare change using gamification for better health and reduced diseases through sustained behaviour change. Buheji (2019a), McGonigal (2011).

Gamification is a great technique that can become an innovative part of our outreach tool kit for a social or behavioural change. Using games and gamification techniques can offer non-profits and public agencies a unique and engaging way to interact with their community to promote change that benefits the individual and society. Rughiniș (2013).

Gamification is becoming more of a scientific approach to social development and change, while it started to influence many decision makers and have its practical use in socio-economic issues. Gamification is about applying game-based thinking to organisation business, processes or new concepts or brands. Through gamification, we create a new experience about the inherent powers within, including the level of focus, observation and persistence. Ryan and Deci (2000). 
Gamification is one of the most important tools today in changing the mindset of the stakeholders and setting effective strategies for social transformation. Through gamification, we can recognise the level of learning and achievement, with relatively informal and immediate feedback in relevance to day-to-day practice. Gamification found to be particularly crucial in non-formal settings.

Gamification as per Buhijji (2017) is very attractive to human mindset, since it is based on incremental, achievable yet challenging goals, that are tracked by points and personal progress analysis.

\section{Methodology}

A synthesis of the literature for the constructs and indicators of gamification of the public healthcare services was carried out. Then a list of the inspiration labs projects carried out published by the author in Buheji (2019a) and Buheji (2018) for healthcare services are listed in the table. Then, the type of gamification techniques and constructs used in the inspiration labs projects are categorised according to the type of healthcare services or sectors: primary care, secondary care (hospitals), public health services, health enrichment and psychiatric services. Then, a review of the type gamification constructs that dominates more the re-invented healthcare activities is presented and discussed. The findings focus on the suitability of gamifying such public services activities through such gamification techniques and constructs. Then a discussion and conclusion are drawn based on this finding.

\section{Case Study}

\subsection{Background about Gamifying the Healthcare Services}

During 2010 till 2016, there were more than 17 projects started in the healthcare services in the Kingdom of Bahrain through what is called inspiration labs. The labs targeted to improve and radically change in collaboration with the public healthcare service providers in their main sectors: primary care, secondary care, public health services, community health enrichment services and public health directorates. Buheji (2018).

Buheji (2018) mentioned all these public healthcare services labs where different gamification approaches were used in relevance to the type of exploration or opportunities utilised. For example, one of the labs focused on the early detection of Non-Communicable Diseases (NCD's), i.e. WHO listed central cardio-vascular related disease: diabetes, blood pressure, cholesterol and obesity. The labs targeted raising the capacity of all the healthcare staff and integrating their efforts in discovering the NCD's patients as early as possible. This led to using gamification techniques that would help to expand the responsibility of healthcare staff through a competition technique called 'Hit Rate'. The idea of the 'Hit-Rate' was to gamify the sense of visual measurement and reward at the end of each day, Domínguez et al. (2013). Each healthcare staff: family physicians, nurses, assistant nurses, healthcare visitors and social workers were asked to compete on quantity and quality of catchment of the NCDs patients, as part of their day to day processes and services. Measurement whiteboards were set in each clinic and treatment rooms to ensure the 
percentage of NCDs discovered, i.e. percentage of hit rate, compared to the number of patients diagnosed or treated or serviced. The results affected the spread of the project throughout all the health centres as it became obvious that with the available resources, the percentages of NCDs risk discovery can increase considerably. This project helped to manage the risk of NCD can start early and can help mitigate the risk of the disease to a later stage in life or avoid it.

\subsection{Type of Gamification Techniques}

Similar to what reviewed and presented in section 3.5, there are more techniques also that are suitable to gamifying the services, as in the healthcare case. For example, this case used techniques as the 'Hit Rate' and codification besides the techniques listed in 3.5. Therefore, the different types of gamification techniques used in the 21 types of labs conducted during four years, in the five healthcare sectors are represented in the third column in Table (1). The table shows how the type of gamification techniques addresses one of the gamification constructs indicators for each type of lab. For example, we would see that labs used, for example, Hit Rates, others used Stickers or batches, etc. Deterding et al. (2013)

Table (1) links all the different healthcare services or sectors to the gamification techniques and constructs indicators.

Table (1) Illustrates the Gamification Techniques used in the different Healthcare Services Activities.

\begin{tabular}{|c|c|c|c|c|}
\hline $\begin{array}{c}\text { Type } \\
\text { Healthcare Services }\end{array}$ & $\begin{array}{l}\text { Type of Gamification Activities } \\
\text { Used in the Inspiration Labs Projects/ } \\
\text { Models }\end{array}$ & $\begin{array}{l}\text { tion } \\
\text { es }\end{array}$ & $\begin{array}{l}\text { Gamifica } \\
\text { Techniqu }\end{array}$ & $\begin{array}{l}\text { Construc } \\
\text { ts Indicators }\end{array}$ \\
\hline $\begin{array}{c}1 . \\
\text { rimary Care }\end{array}$ & $\begin{array}{l}\text { 1-Early detection } \\
\text { Non-Communicable Diseases (NCD's), i.e. } \\
\text { Diabetes, Blood Pressure, Cholesterol and } \\
\text { Obesity through expanding the responsibility } \\
\text { of healthcare staff and defining of 'Hit-Rate' } \\
\text { Competition. } \\
\text { 2-Enhancement of Quality through } \\
\text { Inspiring Families Physicians. } \\
\text { 3-Codifying Patients Self-Triage } \\
\text { according to their level of emergency and } \\
\text { priority of the case in health-centres. } \\
\text { 4-Codify physicians in their capacity } \\
\text { for early detection of Psycho-Sematic in } \\
\text { relevance to Anxiety in Health Centre. } \\
\text { 5-Increase the Health centres } \\
\text { readiness for Emergency Cases. } \\
\text { 6-Optimising the role of Social } \\
\text { Workers and Health Educational Specialist } \\
\text { and Health visitors in family screening. }\end{array}$ & $\begin{array}{l}\text { on } \\
\text { ofing }\end{array}$ & $\begin{array}{l}\text { Codificati } \\
\text { Alertness } \\
\text { Error-Pro }\end{array}$ & $\begin{array}{l}\text { Visual } \\
\text { Storytelling } \\
\text { (1) }\end{array}$ \\
\hline
\end{tabular}




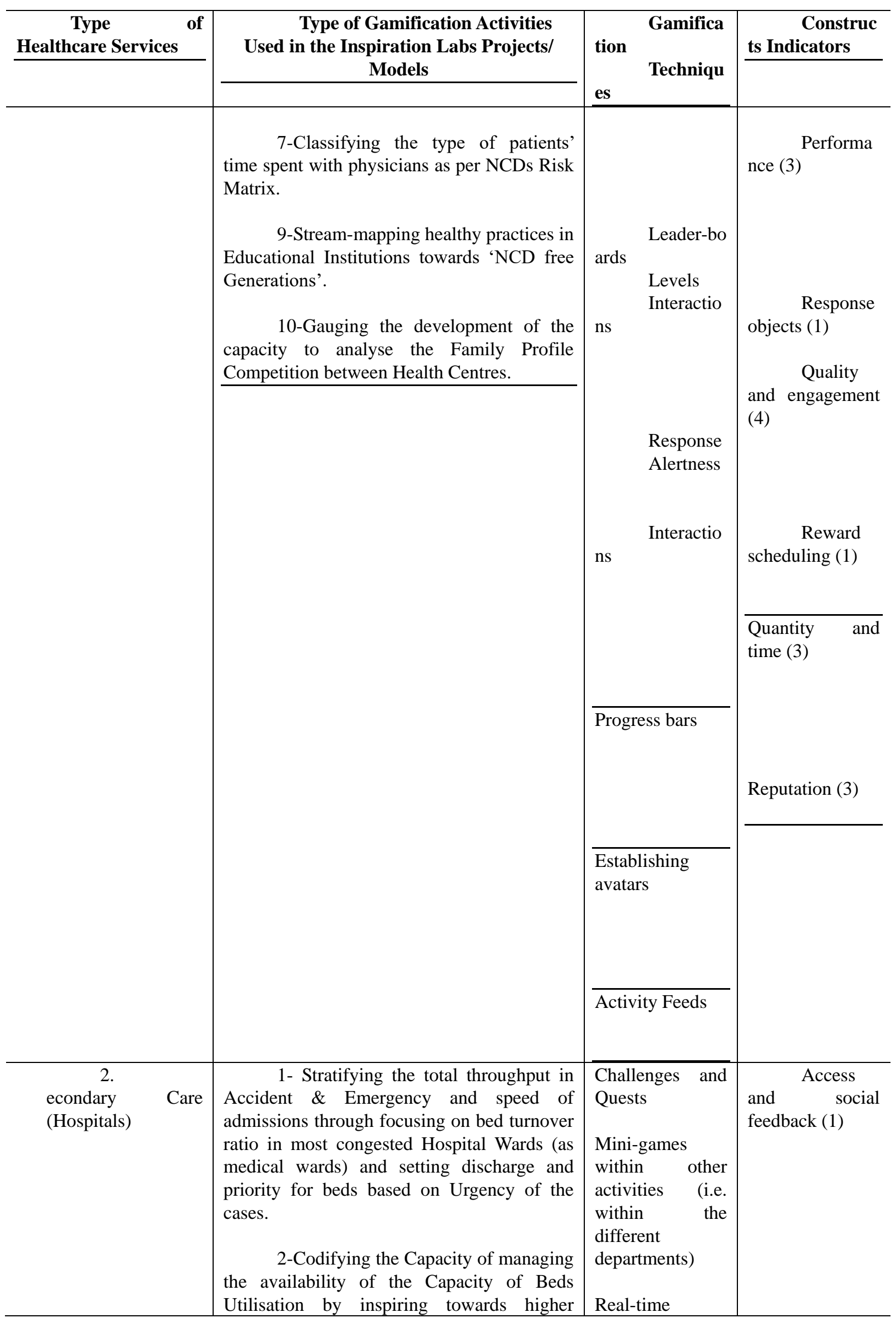




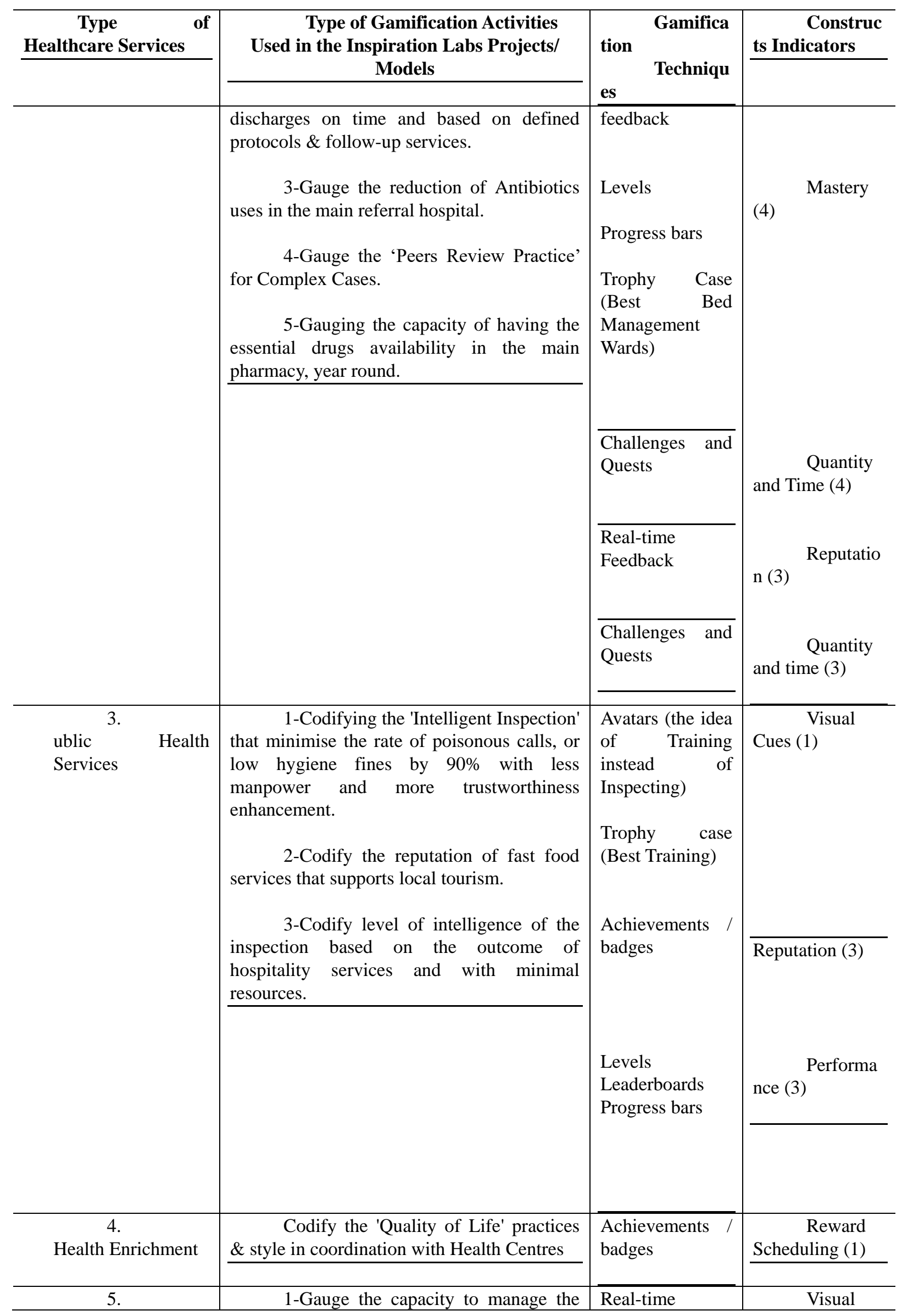




\begin{tabular}{|c|c|c|c|}
\hline $\begin{array}{c}\text { Type of } \\
\text { Healthcare Services }\end{array}$ & $\begin{array}{c}\text { Type of Gamification Activities } \\
\text { Used in the Inspiration Labs Projects/ } \\
\text { Models }\end{array}$ & $\begin{array}{lr} & \text { Gamifica } \\
\text { tion } & \\
& \text { Techniqu }\end{array}$ & $\begin{array}{l}\text { Construc } \\
\text { ts Indicators } \\
\end{array}$ \\
\hline & & & \\
\hline \multirow[t]{3}{*}{ sychiatric Services } & $\begin{array}{l}\text { anxiety to avoid reaching the level of chronic } \\
\text { anxiety. } \\
\text { 2-Gauge suicide ratio due to early } \\
\text { treatment of main causalities among youth. }\end{array}$ & $\begin{array}{l}\text { feedback } \\
\qquad \text { (Through } \\
\text { Self-Assessment } \\
\text { Anxiety Forms) }\end{array}$ & \multirow{2}{*}{$\begin{array}{l}\text { storytelling (1) } \\
\text { nce (3) Performa }\end{array}$} \\
\hline & $\begin{array}{l}\text { 3-Gauge the patients' sick leave due to } \\
\text { self-assessments of psycho-sematic } \\
\text { symptoms }\end{array}$ & $\begin{array}{l}\text { Challenges and } \\
\text { quests }\end{array}$ & \\
\hline & & Activity Feeds & and time (3) \\
\hline
\end{tabular}

Based on the analysis of the primary five constructs we can find 7 of the 21 activities (33\%) to be of mechanical reference, 2 activities (10\%) to be rewards reference, 9 activities (43\%) to be of measurement reference and finally 3 activities (14\%) to be of behaviour reference where the percentages are illustrated in Figure (2).

Figure (2) Illustrates the Type of Constructs used in the Re-Invented Public Healthcare Projects.

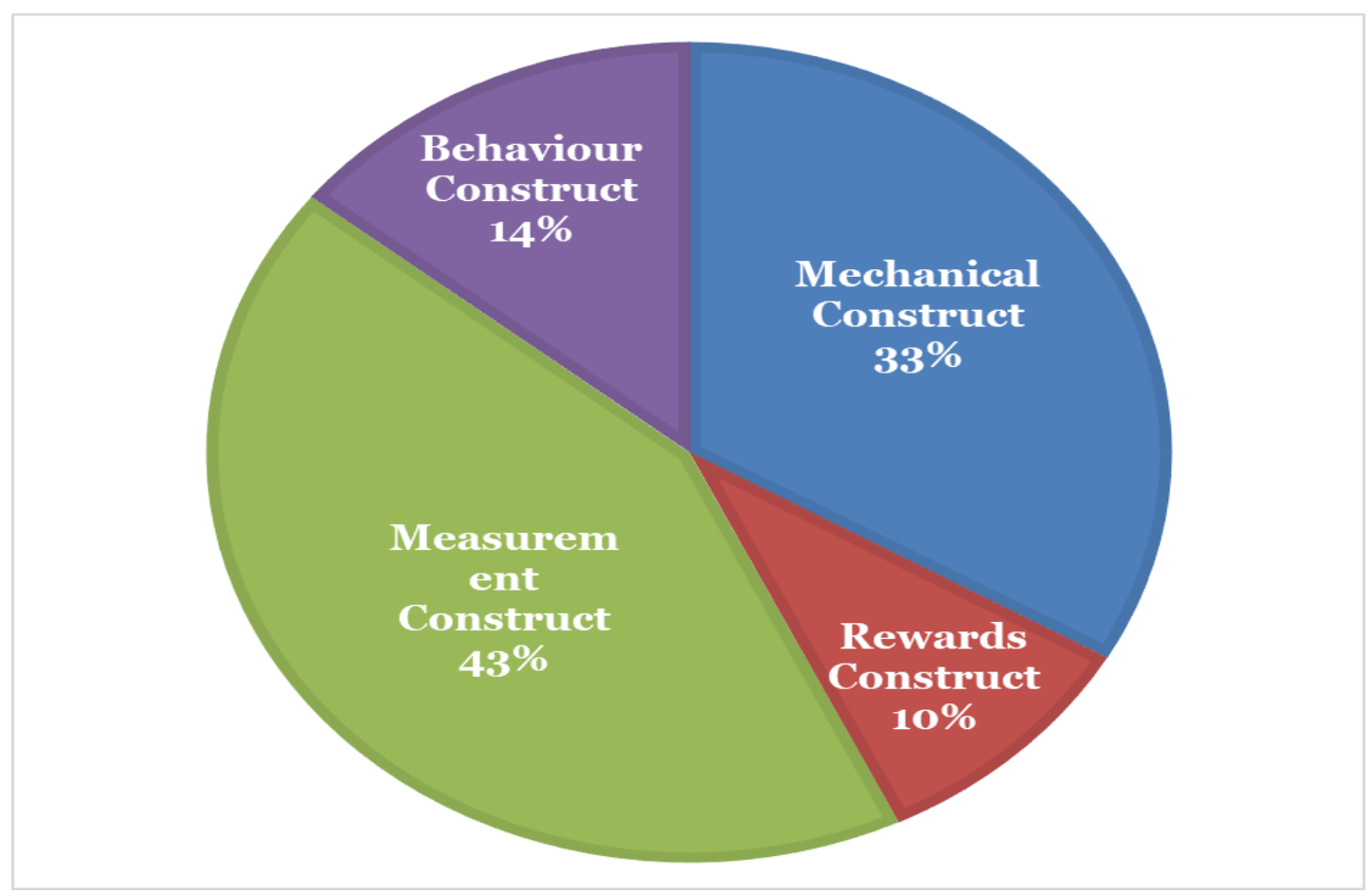

\section{Findings}

Majority of public healthcare services shows to be focused on measurement constructs, followed by mechanical constructs. In this paper, we shall focus mainly on the findings of the measurement and the mechanical constructs as they carry $76 \%$ of the total activities done in 
relevant to labs efforts taken.

The measurement constructs used in the inspiration labs that led to re-inventing the healthcare services, came as a result of the following gamification techniques in relevance to the different activities developed: leader-boards, levels, interactions, establishing avatars, activity feeds, challenges and quests, achievements badges, leaderboards and progress bars.

The mechanical construct is the collective effort of the gamification techniques that are repeatedly were used in the different healthcare services sectors. I.e. in order to achieve the desired goals that lead to re-inventing the way the healthcare services are delivered, techniques as: hit-rate, codification, response alertness, progress bars, challenges and quests along with mini-games within other activities (i.e. within the different departments) were applied. Also, real-time feedback, avatars (i.e. as the idea of training instead of inspecting), trophy case (i.e. competition for best training), achievements badges and real-time feedback, i.e. through self-assessment anxiety forms; were used as part of the mechanical constructs gamification techniques in the healthcare services provided.

\section{Discussion and Conclusion}

This paper shows how gamification could differentiate the health services and re-invent its efficacy. The gamification used in inspiration labs during the four years' projects in the Kingdom of Bahrain shows that there could be many innovative possibilities for healthcare improvement through the techniques and constructs of gamification.

The indirect rewards built as part of the labs and projects approaches helped to align the different services stakeholders, i.e. the medical and healthcare staff. This helped to overcome the challenges of change that usually are faced with professional bureaucratic that are usually available in healthcare organisation and cultures. The different gamification techniques helped avoid the mixed signals about the focus of change and improved the possibility of finding opportunities inside each of the problems in the inspiration labs.

The gamification constructs help to make almost all the interventions psychologically acceptable. The mechanical and measurement constructs gamified $76 \%$ of the healthcare services. Rewards construct constitute $10 \%$ of the gamified healthcare services and helped to balance their speed and accuracy, as in improving the quality of inspiring families' physicians and codifying patients self-triage, according to their level of emergency in health-centres. While the behavioural construct constituted $14 \%$ of the total inspiration labs carried in the different healthcare sectors and was limited to the enhancement of both the social workers and the health visitors in the families screening.

Collectively, all the four constructs helped to effectively gamify the performance of the inspiration lab in re-inventing the healthcare services towards the benefits of early detection of disease, or speeding up the throughput of services, or mitigation of health risks, or improving the accessibility of emergency cases. This means that due to the nature of healthcare, there are many services that can be gamified to the benefits of the patients' safety and quality of life. 


\section{Macrothink Institute ${ }^{\mathrm{TM}}$}

The limitations of this paper are that it is being carried in one country and as part of government inspiration labs. However, the paper does not undermine recommending future studies that would explore further the influence of each gamification construct or indicators on the public healthcare services or similar other critical public services as education, municipality services, transportation, electricity and water supply and even security services. Development of interaction between all the stakeholders of these public services through the gamification techniques could help to further re-invent all these quality of life-related services to the benefit of citizens and the country in general.

\section{References}

Buheji, M. (2018). Re-Inventing Our Lives, A Handbook for Socio-Economic "Problem-Solving", AuthorHouse, UK.

Buheji, M. (2019a). 'The Trust Project' Building better accessibility to Healthcare Services through Behavioural Economics and Inspiration Labs, International Journal of Economics, Commerce and Management, United Kingdom, Vol. VII, Issue 2, February.

Buheji, M. (2019b). Shaping the Anatomy of Socio-Economic Community Problems towards Effective Solutions, Issues in Social Science, 7(1), 1-11.

Buheji, M., \& Ahmed, D. (2017). Breaking the Shield- Introduction to Inspiration Engineering: Philosophy, Practices and Success Stories, Archway Publishing, FROM SIMON \& SCHUSTER, USA.

Buheji, M., \& Ahmed, D. (2018). Exploring Inspiration Economy, AuthorHouse, UK.

Buhijji, A. (2017). The 9 Characters of Creativity, the development of a creativity tool-kit for idea generation in collaborative design projects. Master in Innovation Design Thesis, Brunel University, UK.

Deci, E., \& Ryan, R. (1985). Intrinsic motivation and self-determination in human behavior, Plenum Press, New York. https://doi.org/10.1007/978-1-4899-2271-7

Deterding, S. S., Khaled, R., Nacke, L., \& Dixon, D. (2013). Gamification: Toward a Definition, Proceedings of the CHI 2011, Vancouver, Interaction Design and Architecture(s) Journal - IxD\&A, N.19, pp. 28-37 9.

Deterding, S., Khaled, R., Nacke, L., \& Dixon, D. (2011). From Game Design Elements to Gamefulness: Defining "Gamification", Proceedings of the MindTrek 2011, Tampere. https://doi.org/10.1145/2181037.2181040

Domínguez, A., Saenz-de-Navarrete, J., de-Marcos, L., Fernández-Sanz, L., Pagés, C., \& Martínez-Herráiz, J. (2013). Gamifying learning experiences: Practical implications and outcomes, Computers \& Education, $\quad 63, \quad 380-392$. https://doi.org/10.1016/j.compedu.2012.12.020

Heckhausen, J., \& Heckhausen, H. (2008). Motivation and action: Cambridge University Press, Cambridge. https://doi.org/10.1017/CBO9780511499821 
Hense, J., \& Mandl, H. (2012). Learning in or with games? Quality criteria for digital learning games from the perspectives of learning, emotion, and motivation theory, In: D.G. Sampson, J. M. Spector, D. Ifenthaler \& P. Isaias (eds.), Proceedings of the IADIS International Conference on Cognition and Exploratory Learning in the Digital Age, pp. 19-26, IADIS,

Kapp, K. (2012). The Gamification of Learning and Instruction: Game-based Methods and Strategies for Training and Education, Pfeiffer, San Francisco. https://doi.org/10.1145/2207270.2211316

Madrid, W., \& Hunter, D. (2012). For the Win: How Game Thinking Can Revolutionize Your Business., Wharton Digital Press, Philadelphia.

McClelland, D. C. (2009). Human motivation, Cambridge University Press, Cambridge.

McGonigal, J. (2011). Reality Is Broken: Why Games Make Us Better and How They Can Change the World, Penguin Group, New York

Robinson, D., \& Bellotti, V. (2013). A Preliminary Taxonomy of Gamification Elements for Varying Anticipated Commitment, Proceedings of the CHI, Paris.

Rughiniș, R. (2013). Flexible Gamification in a Social Learning Situation. Insights from a Collaborative Review Exercise, Proceedings of the CSCL 2013, Munich.

Ryan, R., \& Deci, E. (2000). Self-determination theory and the facilitation of intrinsic motivation, social development, and well-being, American psychologist, 55(1), 68-78. https://doi.org/10.1037//0003-066X.55.1.68

Sailer, M., Hense, J., Mandl, H., \& Klevers, M. (2013). Psychological Perspectives on Motivation through Gamification, Interaction Design and Architecture(s) Journal - IxD\&A, 19, 28-37.

Skinner, B. (1963). Operant Behavior, American Psychologist, 18(8), 503-515. https://doi.org/10.1037/h0045185

Werbach, K., \& Hunter, D. (2012). For the Win: How Game Thinking Can Revolutionize Your Business. Philadelphia: Wharton Digital Press.

\section{Copyright Disclaimer}

Copyright for this article is retained by the author(s), with first publication rights granted to the journal.

This is an open-access article distributed under the terms and conditions of the Creative Commons Attribution license (http://creativecommons.org/licenses/by/4.0/). 